Article

\title{
The Influence of Remelting on the Properties of AlSi9Cu3 Alloy with Higher Iron Content
}

\author{
Justyna Kasińska $^{1, *}$, Dana Bolibruchová ${ }^{2}$ and Marek Matejka ${ }^{2}$ \\ 1 Department of Metal Science and Materials Technology, Kielce University of Technology, Al. Tysiąclecia \\ Państwa Polskiego 7, 25314 Kielce, Poland \\ 2 Faculty of Mechanical Engineering, Department of Technological Engineering, University of Žilina, \\ Univerzitná 8215/1, 01026 Žilina, Slovakia; danka.bolibruchova@fstroj.uniza.sk (D.B.); \\ marek.matejka@fstroj.uniza.sk (M.M.) \\ * Correspondence: kasinska@tu.kielce.pl; Tel.: +48-41-34-24-470
}

Received: 4 December 2019; Accepted: 23 January 2020; Published: 25 January 2020

\begin{abstract}
This article aims to evaluate the influence of remelting on the experimental Al-Si-Cu type alloy with higher iron content on mechanical properties in relation to the resulting structure. The remelting or recycling process is one of the means of reducing the production costs of the forge plant. The experimental part deals with the analysis of the results of mechanical properties, structural analysis, and the process of crystallization of structural components and their changes due to the increased iron content caused by remelting at different states of the examined alloy. The effect of remelting and ageing on microstructure was observed using a combination of different analytical techniques (light microscopy, scanning electron microscopy (SEM), and upon deep etching and energy dispersive $\mathrm{X}$-ray analysis (EDX)). Tensile strength and elongation tests point to the negative effect of alloying, a gradual increase in $w t \%$ Fe and a change in the morphology of the iron phases, which began to manifest significantly after the fourth remelting. The process of natural ageing has been shown to be effective only on alloys with a lower number of remelting cycles, whereas the application of artificial ageing has resulted in improved mechanical properties in all the test alloys.
\end{abstract}

Keywords: Al-Si-Cu secondary aluminium alloy; remelting; iron intermetallic; metallography; deep etching; natural and artificial ageing; mechanical properties

\section{Introduction}

Recycling through multiple remelting is a major aspect in the continued lifetime of aluminum alloys. Metallurgy of recycled secondary aluminum alloys, as well as that of many other recycling processes, enables raw material savings and, in particular, energy savings with a profit of up to $95 \%$. Another positive aspect of recycling aluminum alloys is the environmental impact, as only $5 \%$ of greenhouse gases are released in the production process compared to primary aluminum production [1-3]. Depending on the foundry, a few dozen percent of recycled material, such as gating systems, chips, or miscellaneous castings, is used today in the charge $[4,5]$.

The recycled material in the batch will be increasingly used due to the economic and environmental benefits of these alloys in the casting process. A high amount of recycled aluminum material is also used for structural castings with complex shapes, e.g., automotive industry. It is impossible to trace the number of times that the specific portion of the material returns to the casting process. Despite the fact that this material meets all the required criteria given in EN 1706, there is "unwarranted" decrease in the mechanical properties after some time. It is an actual metallurgical topic that distresses foundries. Worldwide, there is a minimum of authors investigating this phenomenon in detail. There are authors [6] who state that aluminum can be recycled indefinitely without losing the desired 
properties associated only with a reduction in the content of some elements and a small change in microstructure and mechanical properties, which appears to be incorrect. However, there are several authors [7] who claim that with the increasing number of remelting, the alloy substantially loses its original properties and there is a significant degradation of structural components with a decrease in mechanical properties. The degradation of the structural components is in many cases unclear. Despite the knowledge gained so far on the effect of multiple remelting regarding the microstructure and the resulting mechanical properties, there is no clear opinion about its impact. For this reason, we have been studying the effects of remelting various Al-Si-Cu-based aluminum alloys for several years.

Due to the increasing use of recycled aluminum alloys for demanding castings, especially for the automotive industry, their quality is considered to be the key factor. The microstructure and mechanical properties of the alloy depend on a number of factors including its chemical composition. The most damaging element is generally considered to be iron, which, with other elements present in the alloy, can form intermetallic phases of a different morphology and length. Depending on the chemical composition of the alloy, the harmful effect of iron occurs when the so-called critical value of $\mathrm{Fe}_{\text {crit }}$ over-ranges in $\mathrm{wt} \%$, which is calculated using Equations [8-11]:

$$
\mathrm{Fe}_{\mathrm{crit}} \approx 0.075 \times(\% \mathrm{Si})-0.05
$$

Several authors have reported the harmful effects of iron phases. In their work, the authors report that the presence of iron-based phases in the alloy structure results in a decrease in ductility and tensile strength. The cause of the harmful influence of intermetallic particles on mechanical properties is that they are much easier to break at tensile loads than the aluminium matrix or small silicon particles (if modified). Increased iron content may increase the hardness of the alloy since iron-based phases achieve higher hardness compared to the primary $\alpha$ phase [12,13].

Copper in this system lowers the liquidus temperature and worsens ductility, improves machinability, and thermal conductivity. The biggest disadvantage is the reduced resistance to corrosion (inter-crystalline type of corrosion), where the main catalyst is the presence of copper and the impact of the environment. There are no ternary compounds in the system [14,15].

The AlSi9Cu3 alloy is characterized by a high degree of mobility of hardening element $(\mathrm{Cu})$ atoms. The natural ageing process proceeds slowly and spontaneously at ambient temperature and the final properties are achieved in more than 100-150 h. After this time, a partially saturated phase $\alpha$ (Al) is formed in the alloy and the strength and hardness of the castings are increased due to spontaneous ageing. In the ageing process, it comes to diffusion of the additive element into the microscopic regions rich in this element and to nucleation of the new phase in them. The growth of these embryos results in coherent precipitates that are referred to as GP zones. Coherence means that these areas are part of a crystalline grid of solid solution, which deforms the grid and induces internal stresses in it, thereby increasing the strength and hardness of the alloy. Artificial ageing temperatures are selected in the range 150 to $200{ }^{\circ} \mathrm{C}$ depending on the alloy, and the hardening time is from 2 to $10 \mathrm{~h}$. The properties of the alloy after hardening depends on the hardening element content $[12,16,17]$.

\section{Materials and Methods}

The secondary AlSi9Cu3 (A226) cast alloy was used to perform the experimental work. The alloy is characterized by medium mechanical properties, good strength at elevated temperatures, and good workability. The alloy has a good running quality and a low tendency to form shrinkages. A dominant part of its usage are castings for the automotive industry that are cast mainly by pressure casting: Cylinder heads and engine blocks, crankshaft cabinets, and other components. The alloy is applied also in the electro-technical industry in various components of electric motors [18].

The alloy was prepared in the form of ingots with a total batch weight of $100 \mathrm{~kg}$. To investigate the effect of a higher iron content upon multiple remelting, iron in $w \mathrm{t} \%$ increased from the original value of $1.08 \mathrm{wt} \%$ to approximately $1.4 \mathrm{wt} \%$. Targeted "contamination" (above the value permitted 
by EN 1706) of the alloy took place at $750 \pm 5^{\circ} \mathrm{C}$ by adding AlFe10 master alloy. The intention was to create large iron-based intermetallic phases in the microstructure, which will be subjected to the effect of multiple remelting. The newly formed alloy with higher iron content was used as a reference alloy with the designation D1 for the next experimental procedure. The chemical composition of the primary AlSi9Cu3 alloy was obtained from the standard (EN 1706), the secondary aluminum alloy (experimental material before addition of $\mathrm{Fe}$ ) and AlSi9Cu3 alloy (D1-after addition of $\mathrm{Fe}$ ) according to the results when using arc spark spectroscopy (Q2 ION, Bunker, Kalkar, Germany) are shown in Table 1. Its chemical composition and the calculated critical iron content for D1 alloy according to Equation (1) are given in Table 1.

Table 1. Chemical composition of primary, secondary, and D1 AlSi9Cu3 alloy (wt\%).

\begin{tabular}{ccccccccccc}
\hline Elements & $\mathbf{S i}$ & $\mathbf{F e}$ & $\mathbf{C u}$ & $\mathbf{M n}$ & $\mathbf{M g}$ & $\mathbf{N i}$ & $\mathbf{Z n}$ & $\mathbf{T i}$ & $\mathbf{C r}$ & $\mathbf{F e}_{\text {crit }}$ \\
\hline $\begin{array}{c}\text { Primary } \\
\text { AlSi9Cu3 }\end{array}$ & $8.0-11.0$ & $0.6-1.1$ & $2.0-4.0$ & 0.55 & $0.15-0.55$ & 0.55 & 1.20 & 0.20 & 0.15 & - \\
$\begin{array}{c}\text { (EN 1706) } \\
\text { Secondary }\end{array}$ & & & & & & & & & & \\
AlSi9Cu3 & 9.563 & 1.081 & 2.206 & 0.184 & 0.426 & 0.092 & 1.160 & 0.038 & 0.027 & 0.667 \\
D1 alloy & 9.441 & 1.414 & 2.174 & 0.174 & 0.429 & 0.090 & 1.158 & 0.035 & 0.024 & 0.658 \\
\hline
\end{tabular}

The alloy melting was carried out in an electric resistance furnace in a steel crucible and it consisted of pouring ingots into the prepared metal molds. A protective graphite coating was applied to prevent direct contact of the aluminium melt with the steel crucible, tools, and mold. After solidification and cooling, these ingots were used as a charge for the following melting without further chemical treatment. This process was repeated six times. After each second melt, samples were cast for selected mechanical properties (static tensile test and Brinell hardness test for 12 pieces) and metallographic evaluation, samples with the designation D3 (after the third remelting), D5 (after the fifth remelting), and D7 (after the seventh remelting) were used. Table 2 shows the changes in $\mathrm{wt} \%$ of the selected elements and the level of critical iron (calculated according to Equation 1) in the investigated alloys D3, D5, and D7. Chemical composition was measured by arc spark spectroscopy. As a result of the melting, a significant increase of the iron content (about 12\%) occurred at the alloy D7 compared to the reference alloy D1. This increase is likely to be due to the insufficient treatment of the steel crucible with paint after each melting, which could cause the contamination of melting with the elements mentioned above, since the aluminium alloy is capable of dissolving iron from unprotected steel tools. All test samples were made under the same conditions. The casting temperature was in the range of $750-760{ }^{\circ} \mathrm{C}$ and the temperature of the metal mold was set at $100 \pm 5^{\circ} \mathrm{C}$. The melt was not vaccinated, modified, or refined. Before casting, only the oxide films were removed mechanically [19].

Table 2. Chemical composition of D3, D5, and D7 alloys (wt \%).

\begin{tabular}{ccccccccccc}
\hline Elements & $\mathbf{S i}$ & $\mathbf{F e}$ & $\mathbf{C u}$ & $\mathbf{M n}$ & $\mathbf{M g}$ & $\mathbf{N i}$ & $\mathbf{Z n}$ & $\mathbf{T i}$ & $\mathbf{C r}$ & $\mathbf{F e}_{\text {crit }}$ \\
\hline D3 alloy & 9.316 & 1.475 & 2.114 & 0.186 & 0.423 & 0.097 & 1.157 & 0.037 & 0.043 & 0.649 \\
D5 alloy & 9.313 & 1.51 & 2.094 & 0.181 & 0.407 & 0.115 & 1.144 & 0.033 & 0.061 & 0.648 \\
D7 alloy & 9.286 & 1.612 & 2.097 & 0.187 & 0.394 & 0.133 & 1.173 & 0.031 & 0.103 & 0.646 \\
\hline
\end{tabular}

The samples $(1 \mathrm{~cm} \times 1 \mathrm{~cm})$ for metallographic observations were prepared by standard metallographic procedures (wet ground, polished with diamond pastes, finally polished with commercial fine silica slurry (STRUERS OP-U, Prague, Czech Republic) from selected tensile specimens (after testing). The microstructure of experimental material was studied using optical microscope Neophot 32 and SEM observation with EDX analysis using scanning electron microscope VEGA LMU II (Tescan, Brno, Czech Republic) linked to the energy dispersive X-ray spectroscopy (EDX analyser Brucker Quantax, Bunker, Kalkar, Germany). Samples were etched by a standard reagent ( $0.5 \% \mathrm{HF})$. Some samples were also deep etched for $30 \mathrm{~s}$ in a $\mathrm{HCl}$ solution in order to reveal the three-dimensional 
morphology of the eutectic silicon and intermetallic phases. The specimen preparation procedure for deep etching consists of dissolving the aluminum matrix in a reagent that will not attack the eutectic components or intermetallic phases. The residuals of the etching products should be removed by intensive rinsing in alcohol. Each sample was subjected to measuring the length of the $\mathrm{Al}_{5} \mathrm{FeSi}_{\text {ferric }}$ phase at 500× magnification.

The process of crystallization of alloys with different degrees of remelting was evaluated by thermal analysis. A K-type (NiCr-Ni) thermocouple placed in the center of a cylindrical metal mold with a diameter of $34 \mathrm{~mm}$ and a height of $50 \mathrm{~mm}$ was used during the measurement. Values were recorded in LabView $2 \mathrm{~Hz}$ software (version 18.5, National Instruments, Austin, TX, USA).

The tensile test was performed in accordance with the STN EN ISO 6892-1 standard on testing machine WDW 20 (Jnkason, Jinan, China) with a maximum load of $20 \mathrm{kN}$ and a constant crosshead feed rate of $2 \mathrm{~mm} / \mathrm{min}$. Samples were made from the casting with turning and milling operations. The Brinell hardness test was performed according to STN EN ISO 6506-1 on testing machine INNOVATEST NEXUS 3002XLM-INV1 (Innovatest, Borgharenweg, Netherlands) with a load of $125 \mathrm{kp}$ (1226 N), $5 \mathrm{~mm}$ diameter ball and a dwell time of $15 \mathrm{~s}$. The Brinell hardness value at each state was obtained as the average of at least six measurements. Samples were taken from the front surfaces of the torn bars from the static pull test.

Each alloy was gradually evaluated in three different states, in the cast state (CS—no additional heat treatment performed). Structural analysis and mechanical testing of cast samples were performed within $24 \mathrm{~h}$ of casting. After natural ageing (NA-about $160 \mathrm{~h}$ at $20^{\circ} \mathrm{C}$ ) and after heat treatment (AA-T5 artificial ageing at $200 \pm 5^{\circ} \mathrm{C}$ for $4 \mathrm{~h}$ and cooling by water to $60 \pm 5^{\circ} \mathrm{C}$ ).

\section{Results}

\section{Evaluation of Microstructure}

\subsubsection{Cast State}

On the reference, the microstructure of alloy D1 containing $1.416 \mathrm{wt} \%$ Fe consists of dendrites $\alpha$-phase (light grey), eutectic Si, and intermetallic Fe-rich phases (Figure 1a). Iron-based intermetallic phases precipitate in the interdendritic and intergranular regions as platelets (appearing as needles in the metallographic microscope). Iron particles are evenly distributed in the interdendritic regions of $\alpha$-phase. After the third remelting, there was a change in their reduction, possibly due to partial fragmentation of the plates and needles of intermetallic phase (Figure 1b). Due to further remelting and increasing $\mathrm{wt} \%$ of Fe (Tables 1 and 2), the number and dimensions of the iron phases have increased and are present exclusively in the needle morphology (Figure 1c,d). The change in eutectic Si morphology began to manifest after the fifth remelting. Smooth and large plate-like particles (Figure 1a, deep etch.) of eutectic Si (typical of the reference alloy D1 and the alloy after the third remelting D3) changed to coarse and polyedra morphology due to further remelting (Figure 1d, deep etch).

Thermal analysis of the examined alloys focused on the evaluation of the effect of multiple remelting on the process of crystallization of iron intermetallic phases and their morphology. In all investigated alloys, the critical iron level (1) was exceeded, resulting in the formation of undesirable iron-based intermetallic phases in the alloy structure preferably before the eutectic phases (Figure 2).

Significant change of course of reaction, increase in temperature, and prolongation of iron-based intermetallic phase formation are observed gradually increasing the number of remelting. From the curves of the first derivative, a gradual increase of the peak of the curve is visible in the region characterized by the formation of iron-rich phases, indicating that at higher w $\mathrm{t} \%$ Fe is released at a greater amount of latent heat during the crystallization of these phases. The process of multiple remelting did not significantly affect the temperature changes of the other structural components. (Table 3). 


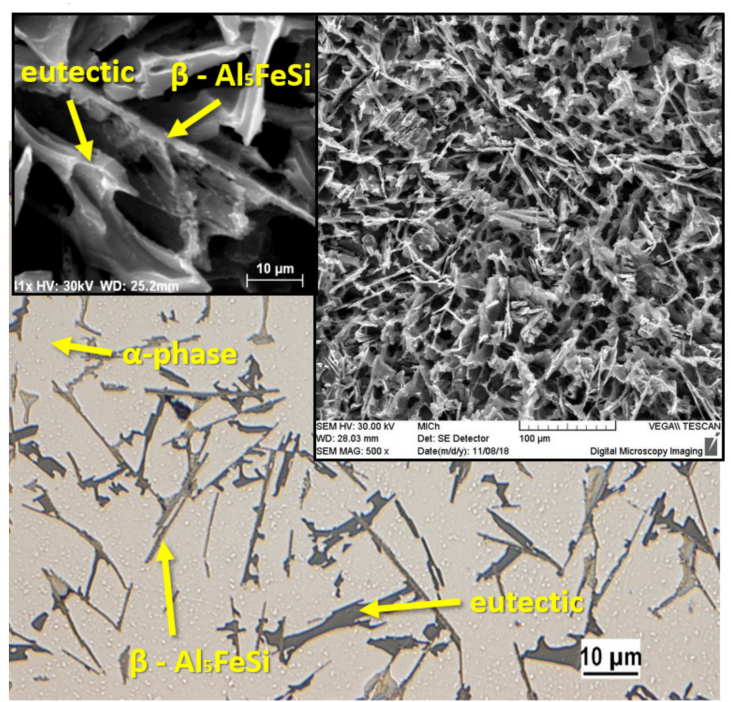

(a)

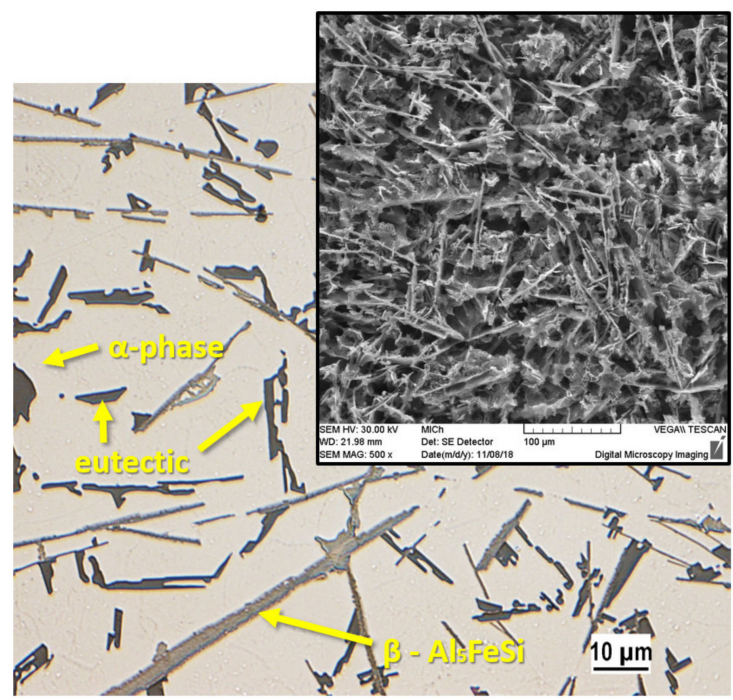

(c)

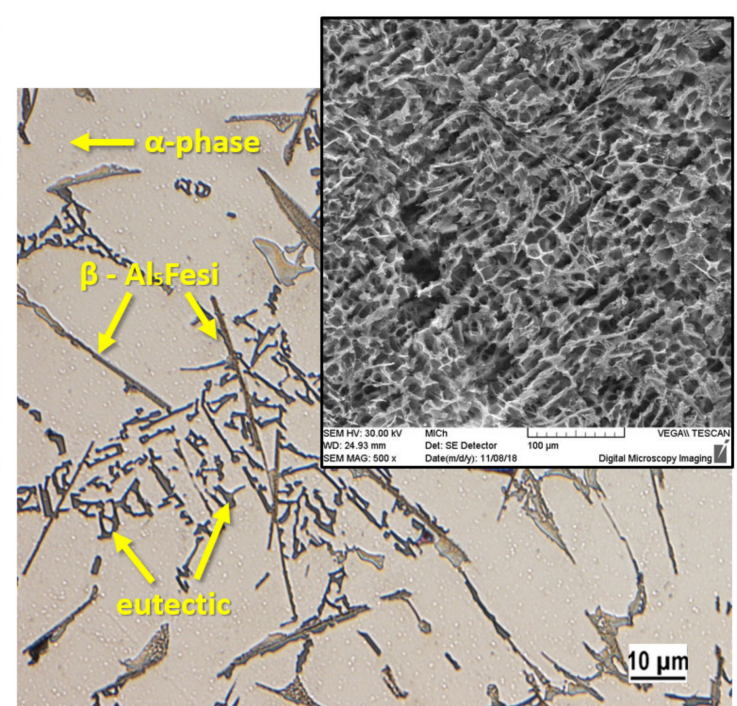

(b)

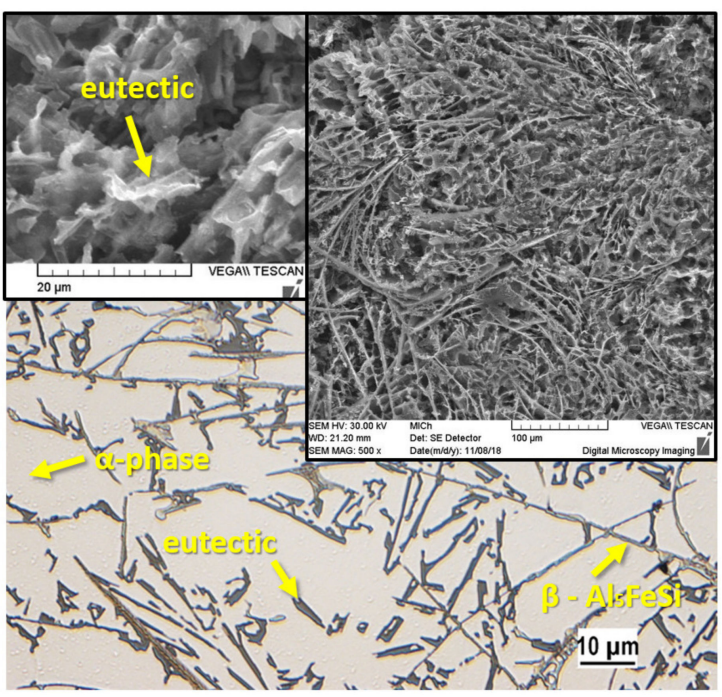

(d)

Figure 1. Microstructure of experimental AlSi9Cu alloy depending on the number of remelting in cast state; optical microscopy, etch 0.5\%; deep etch, SEM. (a) D1 alloy; (b) D3 alloy; (c) D5 alloy; (d) D7 alloy.

Table 3. Characteristic temperatures of investigated alloys.

\begin{tabular}{cccccc}
\hline Alloy & $\mathbf{T}_{\text {liq }}\left({ }^{\circ} \mathbf{C}\right)$ & $\mathbf{T}_{\text {Al5FeSi }}\left({ }^{\circ} \mathbf{C}\right)$ & $\mathbf{T}_{\text {Al-Si }}\left({ }^{\circ} \mathbf{C}\right)$ & $\mathbf{T}_{\text {Al-Cu }}\left({ }^{\circ} \mathbf{C}\right)$ & $\mathbf{T}_{\text {sol }}\left({ }^{\circ} \mathbf{C}\right)$ \\
\hline D1 & 632 & 578 & 569 & 515 & 478 \\
D3 & 629 & 582 & 571 & 517 & 476 \\
D5 & 628 & 584 & 574 & 520 & 477 \\
D7 & 630 & 586 & 573 & 518 & 474 \\
\hline
\end{tabular}




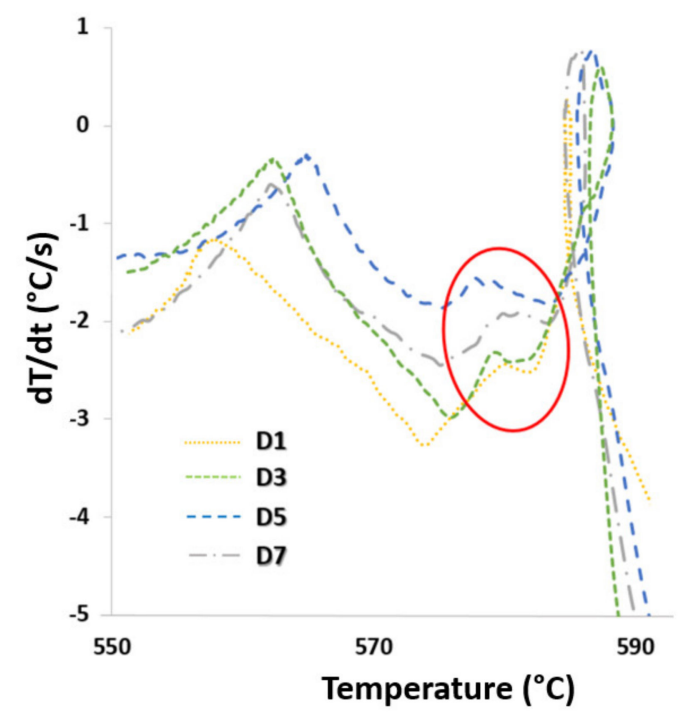

Figure 2. Iron reach phases detected using first derivative curves of AlSi9Cu3 alloys in various degrees of remelting.

\subsubsection{Natural Ageing}

The ASM Handbook [20] claims that two types of iron-rich phases $\left(\alpha-\mathrm{Al}_{15}(\mathrm{FeMn})_{3} \mathrm{Si}_{2}\right.$ and $\beta$ - $\mathrm{Al}_{5} \mathrm{FeSi}$ ) may occur in AlSi9Cu3 alloys. The structure of the reference alloy D1 and alloy D3 after the third remelting is formed by intermetallic phases $\beta-\mathrm{Al}_{5} \mathrm{FeSi}$, whose morphology, due to natural ageing has not changed (Figure $3 \mathrm{a}$ ). The SEM image shows the regular distribution of thin $\beta-\mathrm{Al}_{5} \mathrm{FeSi}$ needles with a monoclinic crystal structure, which are interlaced with silicon plates. The EDX of D1 reference alloy after natural ageing particles is shown in Figure $4 . \mathrm{Al}, \mathrm{Si}, \mathrm{Fe}$, and only a small amount of $\mathrm{Mn}$ was identified in the needle particle, confirming the presence of the $\beta-\mathrm{Al}_{5} \mathrm{FeSi}$ phase. Table 4 shows the mean measured length of $\beta-\mathrm{Al}_{5} \mathrm{FeSi}$ phase needles for each alloy after natural ageing. The particles of eutectic $\mathrm{Si}$ are present in the unmodified form of large hexagonal plates with visible twinning, which are in the form of needles (Figure 3b). On the surface of the eutectic Si plates there are protruding irregular steps related to the twinning of the Si crystal.

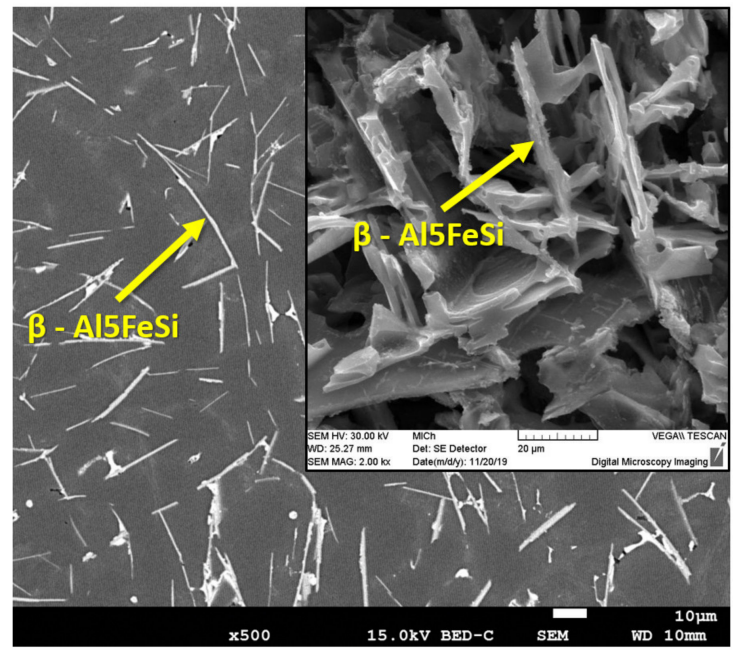

(a)

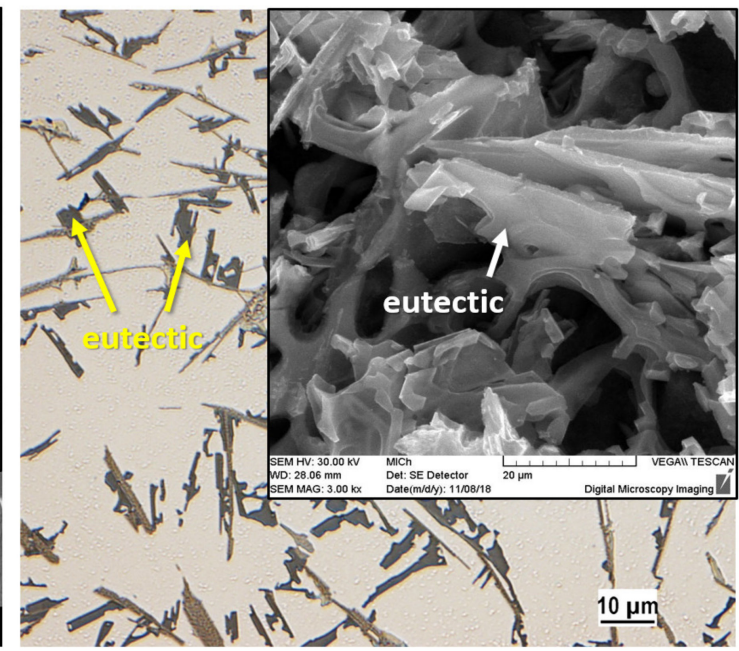

(b)

Figure 3. Microstructure of D1 reference alloy after natural ageing, SEM. (a) Deep etch, SEM; (b) optical microscope, deep etch, SEM. 


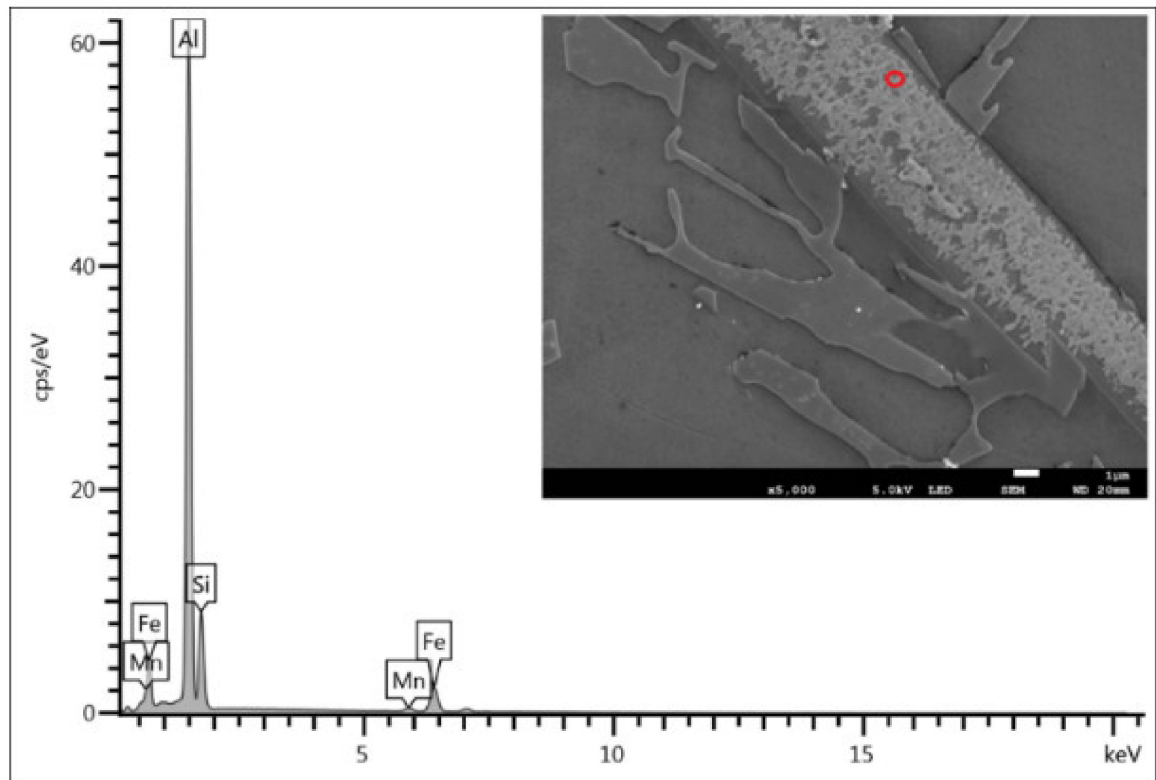

Figure 4. EDX point analysis of $\beta-\mathrm{Al}_{5} \mathrm{FeSi}$ particles of D1 reference alloy after natural ageing, SEM.

Table 4. Measurement results of length of iron-based particles after natural ageing.

\begin{tabular}{ccccc}
\hline Alloy & D1 & D3 & D5 & D7 \\
\hline Average length of iron phases $(\mu \mathrm{m})$ & 55.7 & 27.7 & 71.4 & 89.4 \\
\hline
\end{tabular}

The structures of alloys after the fifth remelting D5 and seventh remelting D7 after natural ageing are characterized (as cast state) by the presence of $\beta-\mathrm{Al}_{5} \mathrm{FeSi}$ phases. The $\beta-\mathrm{Al}_{5} \mathrm{FeSi}$ phases are present (by the metallographic microscope observation) in thicker needle morphology (locally occurring also in the form of platelets) with an increase in their lengths (Table 4), which are even distributed in the aluminum matrix (Figure 5a). Due to the higher number of remelts, eutectic Si crystallized in the form of thick hexagonal plates with undirected distribution or polyedra grain form (Figure 5b). Irregular multiple twinning can be seen on hexagonal plates.

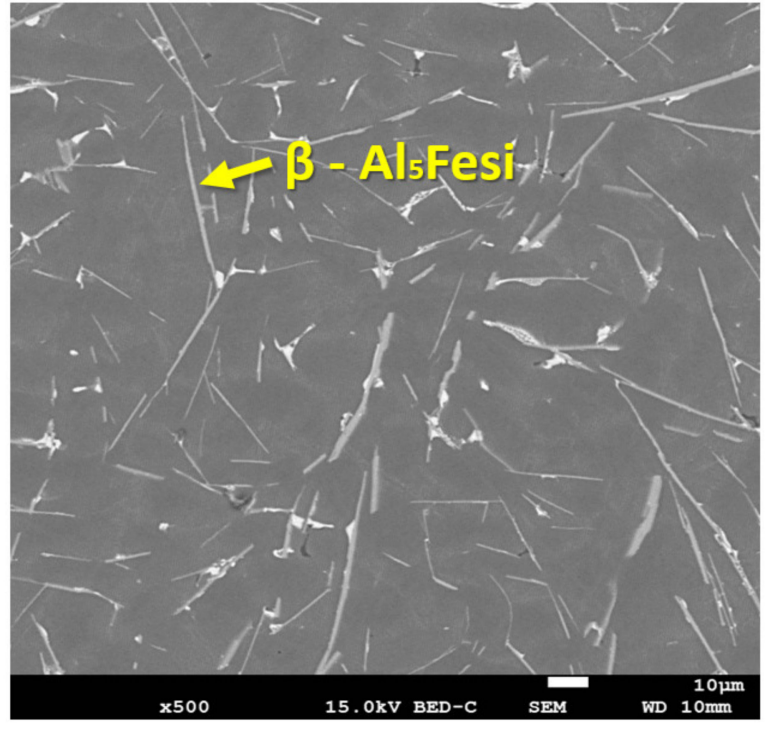

(a)

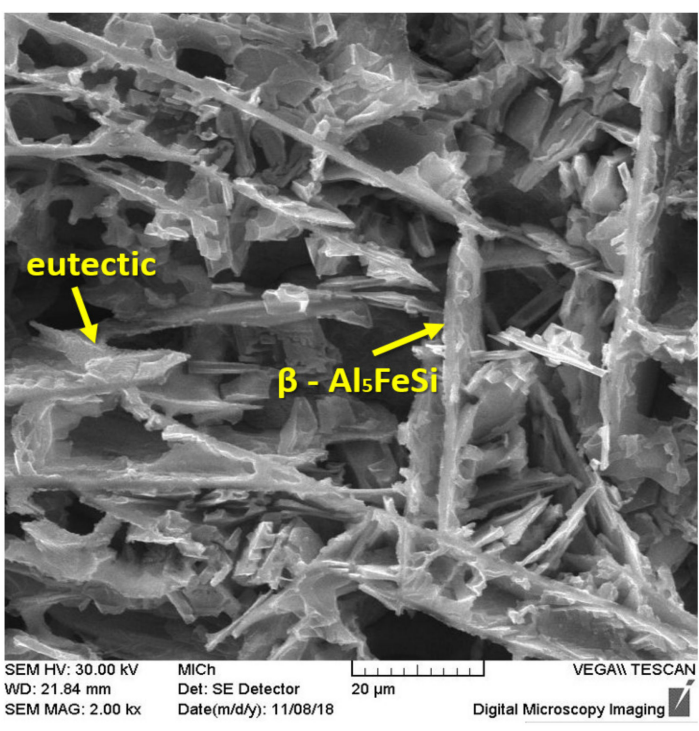

(b)

Figure 5. Microstructure of D5 alloy after natural ageing. (a) SEM; (b) deep etch SEM. 
The experimental material belongs to Al-Si-Cu materials. $\mathrm{Cu}$ is in Al-Si-Cu cast alloys present primarily as phases: $\mathrm{Al}_{2} \mathrm{Cu}, \mathrm{Al}-\mathrm{Al}_{2} \mathrm{Cu}-\mathrm{Si}$, as well as in the presence of Fe type $\mathrm{Al}_{7} \mathrm{FeCu}$ [21]. Intermetallic phases that contain a rich amount of copper and are included in all experimental alloys are primarily eliminated in the vicinity of eutectic silicon grains and, in particular, iron phase needles (Figure 6). The hardening phases of $\mathrm{Al}_{2} \mathrm{Cu}$ can be eliminated in two forms, namely in the so-called "blocks" wherein the intermetallic compound contains about $40 \mathrm{wt} \% \mathrm{Cu}$. The second form is a finely released eutectic containing about $24 \mathrm{wt} \%$ copper released with aluminum. Based on the EDX point analysis (Figure 5a), it can be concluded that the phase $\mathrm{Al}_{2} \mathrm{Cu}$ observed is released in the form of a fine eutectic.

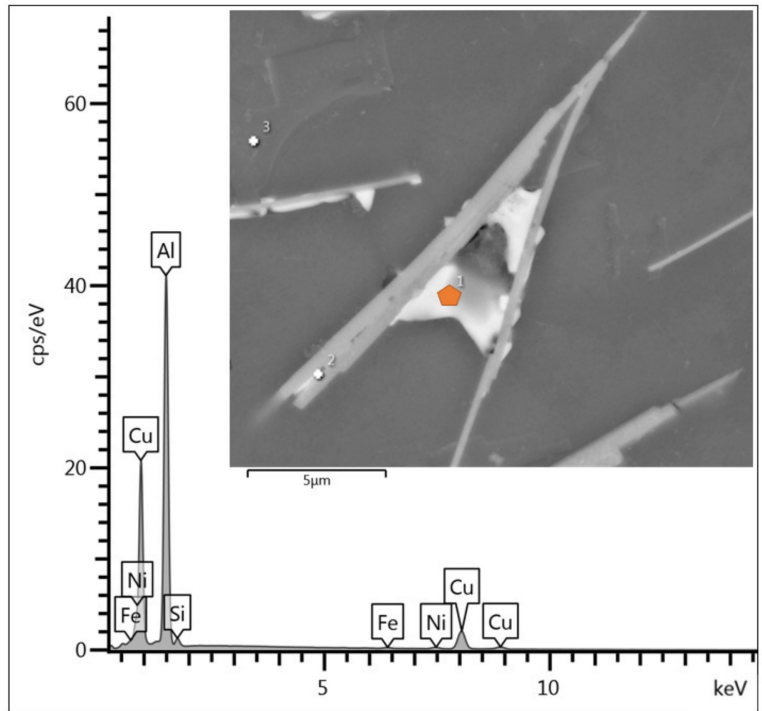

(a)

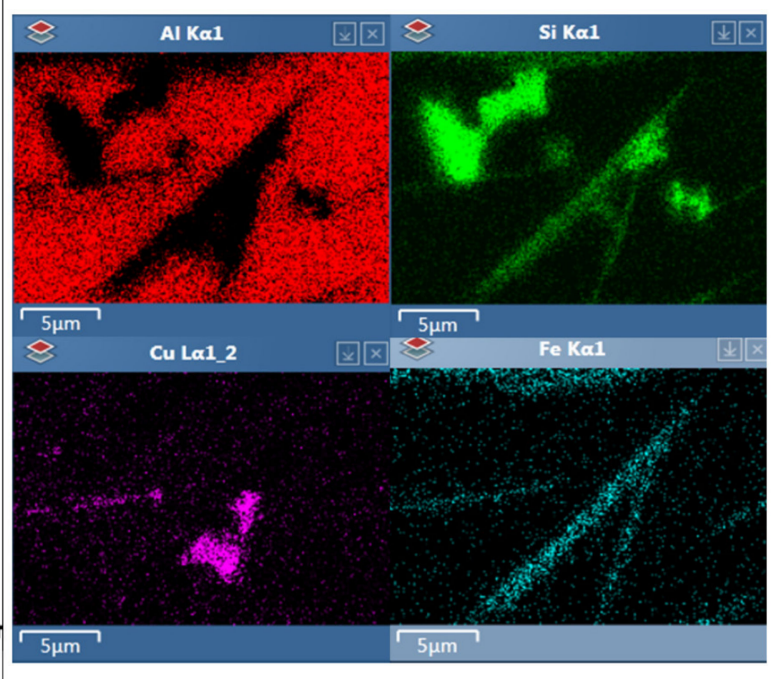

(b)

Figure 6. Copper and iron rich area of precipitation, alloy after 5th remelting D5 after natural ageing. (a) EDX point analysis of $\mathrm{Al}_{2} \mathrm{Cu}$ particles, $\mathrm{SEM}$; (b) mapping elements of various structural components.

\subsubsection{Artificial ageing-T5}

The effect of artificial ageing led to a local refinement and shortening of the iron phase needles compared to natural ageing (Table 5). As a result of artificial ageing, the shape of the eutectic silicon on the alloy has changed on reference alloy D1, after the third D3 and the fifth D5 remelting (Figure 7a,b,c). From the hexagonal plate morphology (typical of alloys after natural ageing), the edges grew and gradually arched and thinned, between the dimensional shape of $\beta-\mathrm{Al}_{5} \mathrm{FeSi}$ phases. In the alloys D1 and D3 (Figure 7a,b), branching and splitting of eutectic Si plates can also be seen. In the alloy after the seventh remelting of D7, artificial ageing caused only local growth of the edges with arching without subsequent thinning (Figure 7d).

Table 5. Measurement results of length of iron-based particles after artificial ageing.

\begin{tabular}{ccccc}
\hline Alloy & D1 & D3 & D5 & D7 \\
\hline Average length of iron phases $(\mu \mathrm{m})$ & 37.8 & 26.3 & 55.1 & 72.6 \\
\hline
\end{tabular}

We observed intermetallic phases $\mathrm{Al}_{7} \mathrm{FeCu}_{2}\left(\mathrm{~L}+\mathrm{Al}_{7} \mathrm{FeCu}_{2} \rightarrow(\mathrm{Al})+\mathrm{Al}_{2} \mathrm{Cu}+\mathrm{Al}_{5} \mathrm{FeSi}\right)$ in the alloys after the fifth and, especially, the seventh remelting (Figure 8a) [22]. The D7 alloy sample, after its seventh remelting, was subjected to a linear EDX method where the composition of the individual phases present in the structure was identified (Figure 8b). The chemical composition of the excluded intermetallic phase of the needled morphology exhibits $\mathrm{Al}, \mathrm{Cu}$, and Fe elements, i.e., it can be the $\mathrm{Al}_{7} \mathrm{FeCu}_{2}$ phase. The second observed phase (on the right side) is mostly composed of $\mathrm{Al}$ 
and $\mathrm{Cu}$ elements, confirming the presence of the $\mathrm{Al}_{2} \mathrm{Cu}$ (containing about $24 \mathrm{wt} \%$-fine eutectic) hardening phase.

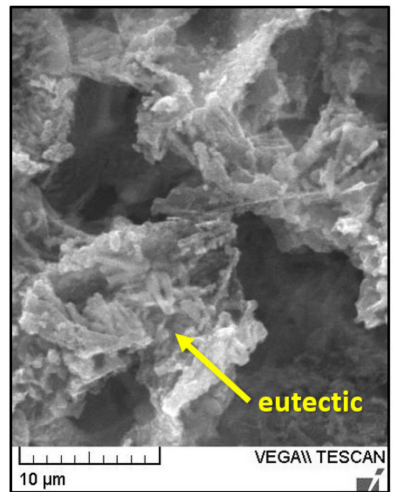

(a)

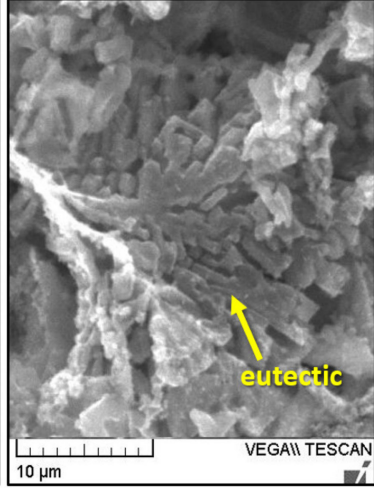

(b)

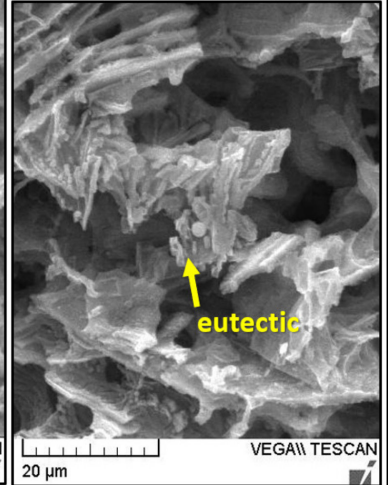

(c)

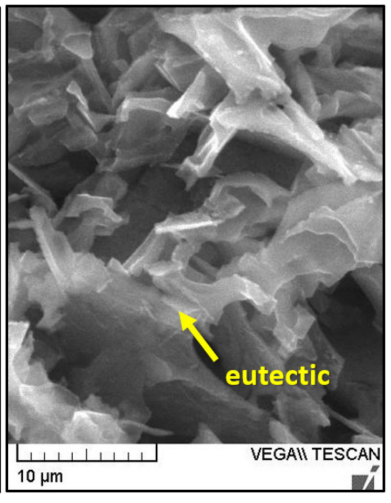

(d)

Figure 7. Eutectic silicon after deep etching of experimental alloys after artificial ageing, SEM. (a) D1 alloy; (b) D3 alloy; (c) D5 alloy; (d) D7 alloy.

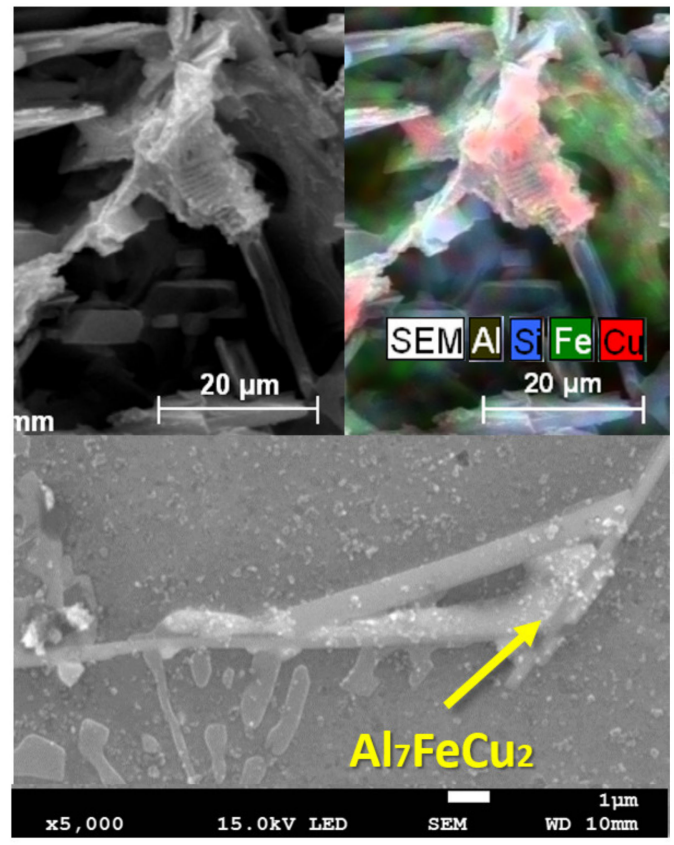

(a)

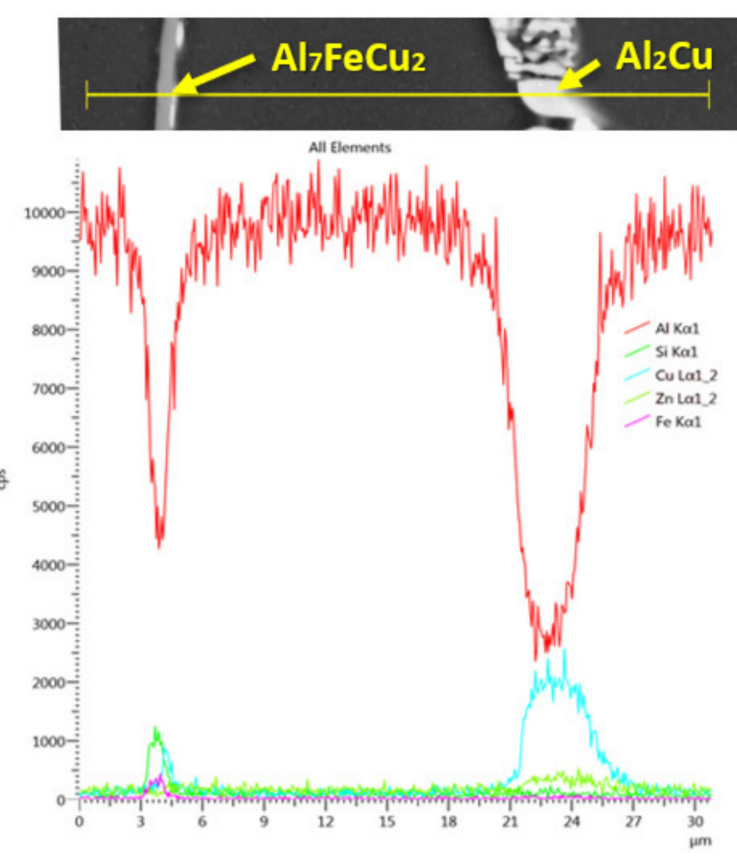

(b)

Figure 8. Microstructure of D7 alloy after artificial ageing. (a) $\mathrm{Al}_{7} \mathrm{FeCu}_{2}$ phase, deep etch, SEM; (b) line EDX analysis of D7 alloy after artificial ageing, SEM.

\subsubsection{Mechanical Properties}

The results of the tensile and elongation tests are graphically shown in Figure 9. The numeric values represent the arithmetic mean of four measurements for each state. The maximum tensile strength $R_{m}=193 \mathrm{MPa}$ (Figure 9a) and the elongation $A_{50}=1.3 \%$ (Figure 9b) of cast alloys were achieved after the third remelting D3. Due to the subsequent remelting there was a rapid decrease of the two investigated characteristics to the minimum values achieved on the alloy after the seventh remelting D7 $\left(\mathrm{R}_{\mathrm{m}}=144 \mathrm{MPa}, \mathrm{A}_{50}=0.5 \%\right)$. Degradation of tensile strength and elongation can be attributed to an increasing iron content, and hence increased iron phases ( $\left.\beta-\mathrm{Al}_{5} \mathrm{FeSi}\right)$ in the offset needle morphology in the structure with a higher number of remelting, thereby disturbing the structure. 
The tensile strength on the reference alloy D1 increased after natural ageing $R_{m}=182 \mathrm{MPa}$ and after artificial ageing $R_{m}=186 \mathrm{MPa}$ (an increase of $4 \%$ compared to cast state). On the alloy after the third remelting D3, due to natural and artificial ageing an increase in both cases was recorded by about $1 \%$ compared to the cast state. A fundamental change occurred on the alloys after the fifth D5 and after the seventh remelting D7. Artificial ageing resulted in an increase in tensile strength to $\mathrm{Rm}$ value $=174$ MPa (an increase by 18\% compared to the cast state) on the alloy after the fifth remelting D5 and on the alloy after seventh remelting D7 to $R_{m}$ value $=165 \mathrm{MPa}$ (increase by $15 \%$ compared to the cast state), while the results of tensile strength of the alloys after the fifth remelting D5 and after the seventh remelting D7 after natural ageing have not improved and the resulting tensile strength values ranged at the same level as in the cast state. After applying the natural and artificial ageing, the decrease of elongation was minimized in all cases. The red line in the graphs indicates the minimum values required by the standard (EN 17 06) for the gravity cast AlSi9Cu3 alloy. The minimum required elongation according to the EN 1706 standard $\left(\mathrm{A}_{50}=1 \%\right)$ was achieved only on the reference alloy and after the third remelting in the cast state and after natural ageing.

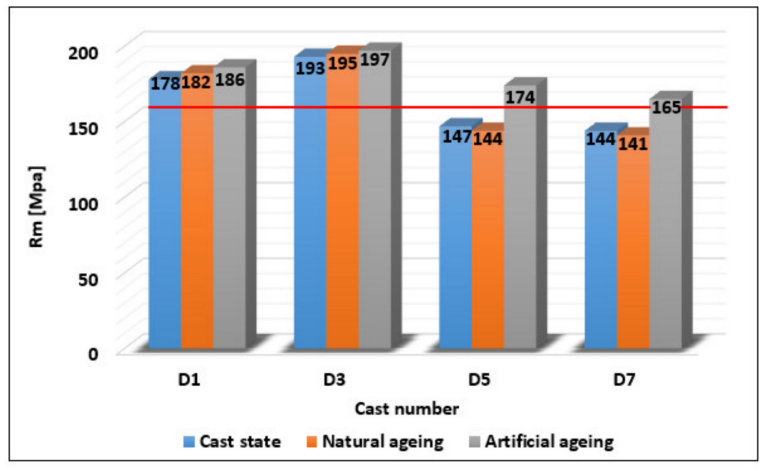

(a)

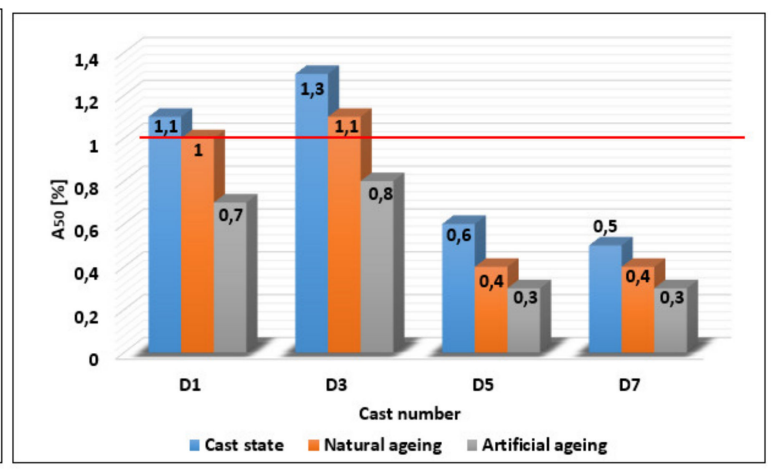

(b)

Figure 9. Relationship between (a) tensile strength and (b) elongation and melt number and alloy state.

On the basis of the hardness results (Figure 10) it can be stated that by the effect of remelting, these did not change significantly. Artificial ageing has led to a single significant change in hardness only for alloys with a higher number of remelting. The increase in hardness for alloys after the fifth D5 and after the seventh remelting D7 may be due to the presence of a large amount of iron phases and possibly also sludge phases in the structure of the alloys characterized by increased hardness. The hardness results on all samples comply with the EN 1706 standard.

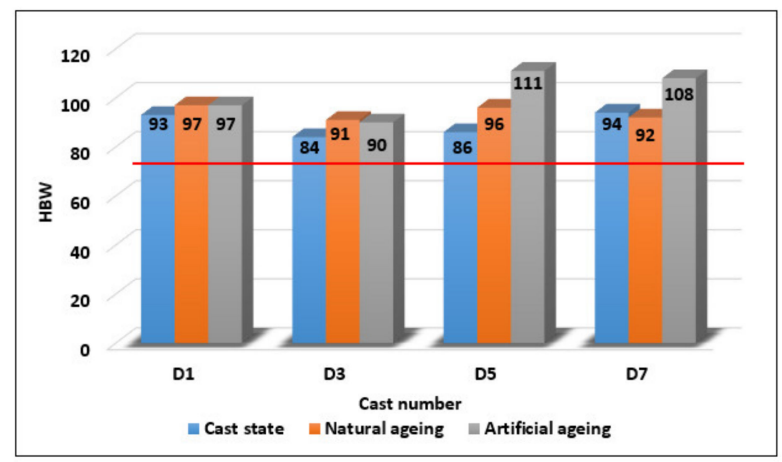

Figure 10. Relationship between Brinell hardness and melt number and alloy state.

\section{Discussion}

As a result of remelting the examined AlSi9Cu3 alloy, it was assumed that there were negative changes in tensile strength and elongation after the third remelting. This phenomenon is a consequence 
of changes in the morphology of the excluded $\beta-\mathrm{Al}_{5} \mathrm{FeSi}$ iron phase. The presence of undesirable needle morphology in alloys with a higher number of remelting results in the distortion of the structure by formation of pre-cracks and it is assumed, for example, to increase the porosity. Along with the increasing $\mathrm{wt} \%$, iron (Table 2) also increases the number and dimensions of $\beta-\mathrm{Al}_{5} \mathrm{FeSi}$ phase. A larger number of these phases degrade in the strength and elongation, as they are characterized by higher brittleness and at the tensile load they are more susceptible to fracture than the aluminum matrix $[8,9,16]$. The significant occurrence of oxidic films has not been observed with an increasing amount of recycled material (see microstructure). On the basis of indirect methods such as (density index) a slight increase in gas amount was measured for alloys with a higher number of remelting and it is possible to assume fixation of oxide films on the formed bubbles, which may also negatively affect the mechanical properties [23-25].

The application of artificial ageing has led to improved mechanical properties in all alloys. On the alloy after the fifth remelting D5, the improvement is by about $18 \%$, and on the alloy after seventh remelting D7 it is by about 15\%. Participating in the above increase has been by the occurrence of the shortening of the dimensions of $\beta-\mathrm{Al}_{5} \mathrm{FeSi}$ phase needles, compared to the samples aged naturally and, probably, a greater incidence of coherent and semi-coherent phases formed due to artificial ageing. The formation and presence of these phases causes deformation of the basic matrix and thus affects the mechanical and physical properties of the alloy $[15-17,26]$. Small precipitates incipient by age-hardening were invisible in the optical microscope and electron microscope so it is necessary to observe them using TEM microscopy [17].

Improving tensile strength through natural ageing is only observed in alloys with a lower number of remelting (D1 and D3), the efficiency of which is comparable to artificial ageing. A fundamental change occurred in alloys after the fifth and seventh remelting, when the tensile strength results reached the level of the cast state.

\section{Conclusions}

Investigating changes in mechanical properties and structural changes due to AlSi9Cu3 alloy remelting can be termed as critical after the fourth remelt. After the fourth remelting, significant degradation of the structural components is observed. The iron-rich phases of alloys with five and more remelting crystallize in the form of thicker needles with significantly larger average lengths. Due to the increasing number of remelts, a significant destruction (degradation) of eutectic silicon from predominantly regular hexagonal plates to irregular polyhedral-type morphology occurred. The change of the structural components had a fundamental effect on the decrease of mechanical properties and especially the ductility of experimental alloys. The application of natural ageing had no major effect on the individual structural components, and similar mechanical properties were achieved compared to the casted state. The application of artificial ageing resulted in a reduction of the iron-rich phase average needle lengths and partial spheroidization of eutectic silicon, resulting in an increase of mechanical properties in all test alloys.

The use of alloys with a higher number of remelting, let us say with higher contamination for the production of dimensionally challenging molded castings is possible by using a suitable method of elimination. As a suitable way to achieve the desired characteristics, the application of $\mathrm{T} 5$ heat treatment was demonstrated by artificially ageing.

Author Contributions: Conceptualization, D.B. and J.K.; methodology, M.M. and D.B.; software, M.M.; validation, D.B., M.M. and J.K.; formal analysis, J.K. and D.B.; investigation, M.M. and J.K.; resources, J.K and D.B.; data curation, M.M. and J.K.; writing-original draft preparation, J.K. and M.M.; writing-review and editing, D.B., J.K. and M.M.; visualization, M.M.; supervision, D.B.; project administration, D.B.; funding acquisition, J.K. and D.B. All authors have read and agreed to the published version of the manuscript.

Funding: The article was created as part of the VEGA grant agency project: 1/0494/17. The authors thank the agency for their support.

Conflicts of Interest: The authors declare no conflict of interest. 


\section{References}

1. Global Aluminum Recycling: A Cornerstone of Sustainable Development. Available online: http://www. world-aluminium.org/media/filer_public/2013/01/15/fl0000181.pdf (accessed on 4 December 2019).

2. Das, S.K.; Gren, J.A.S. Aluminum Industry and Climate Change-Assessment and Responses. JOM 2010, 62, 27-31. [CrossRef]

3. Ciu, J.; Roven, H.J. Recycling of automotive aluminum. Trans. Nonferrous Met. Soc. China 2010, 20, $2057-2063$.

4. Taylor, J.A. Iron-containing intermetallic phase in Al-Si based casting alloys. Procedia Mater. Sci. 2012, 1, 19-33. [CrossRef]

5. Zoloterevsky, V.S.; Belov, N.A.; Glazoff, M.V. Casting Aluminum Alloys 1st Edition. Elsevier Science: Amsterdam, The Netherlands, 2007.

6. Kuchariková, L.; Tillová, E.; Bokůvka, O. Recycling and properties of recycled aluminium alloys used in the transportation industry. Transp. Problem. 2016, 11, 117-122. [CrossRef]

7. Cagala, M.; Bruška, M.; Lichý, P.; Beňo, J.; Špirutová, N. Influence of aluminium-alloy remelting on the structure and mechanical properties. Mater. Technol. 2013, 47, 239-243.

8. Taylor, J.A.; Schaffer, G.B.; StJohn, D.H. The role of iron in porosity formation in Al-Si-Cu based casting alloys - Part I: Initial experimental observations. Metall. Mater. Trans. 1999, 30, 1643-1650. [CrossRef]

9. Cao, X.; Campbell, J. Morphology of $\beta-\mathrm{Al}_{5} \mathrm{FeSi}$ phase in Al-Si cast alloys. Mater. Trans. 2006, 47, 47-1303. [CrossRef]

10. Mbuya, T.O. Influence of iron on castability and properties of aluminium silicon alloys. Int. J. Cast Met. 2003, 16, 451-465. [CrossRef]

11. Ferraro, S.; Bjurenstedt, A.; Seifrddine, S. On the formation of Sludge intermetallic particles in secondary aluminium alloys. Metall. Mater. Trans. A 2015, 46, 3713-3722. [CrossRef]

12. Tillová, E.; Hurtalová, L.; Chalupová, M. The structure analysis of secondary (recycled) AlSi9Cu3 cast alloy with without heat treatment. Eng. Trans. 2013, 61, 197-218.

13. Bolibruchová, D.; Podprocká, R.; Pastirčák, R.; Major-Gabryś, K. The role of Mn in aluminium alloys with a higher iron content. Arch. Metall. Mater. 2018, 64, 1883-1888.

14. Djurdjevic, M.B.; Odanovic, Z.; Talijan, N. Characterization of the Solidification Path of AlSi5Cu(1-4 wt.\%) Alloys Using Cooling Curve Analysis. J. Met. 2011, 63, 51-57. [CrossRef]

15. Bolibruchová, D.; Macko, J.; Bruna, M. Elimination of negative effect of Fe in secondary alloys AlSi6Cu4 (EN AC 45 000, A 319) by nickel. Arch. Metall. Mater. 2014, 59, 717-721. [CrossRef]

16. Bolibruchová, D.; Pastirčák, R. Foundry metallurgy of non-ferrous metals. Publishers of University of Žilina EDIS - Publishers Center of University of Žilina: Žilina, 2018. (in Slovak)

17. Fabrizi, A.; Capuzzi, S.; De Mori, A.; Timelli, G. Effect of T6 Heat Treatment on the Microstructure and Hardness of Secondary AlSi9Cu3(Fe) Alloys Produced by Semi-Solid SEED Process. Metals 2018, 8, 750. [CrossRef]

18. Vončina, M.; Močnik, N.; Nagode, A.; Stoić, A.; Bizjak, M. Dependence of mechanical properties on Cu content in AlSi9Cu3(Fe) alloy. Tehnički vjesnik 2017, 24, 229-231.

19. Bolibruchová, D.; Matejka, M.; Kuriš, M. Analysis of the Impact of the Change of Primary and Secondary AlSi9Cu3 Alloy Ratio in the Batch on its Performance. Manuf. Technol. 2019, 19, 734-739. [CrossRef]

20. Vander Voort, G.F. ASM Metals Handbook Metallography and Microstructures; ASM International: Almere, The Netherlands, 2004.

21. Samuel, A.M.; Doty, H.W.; Samuel, F.H. Factors Controlling the Type and Morphology of Copper-Containing Phases in the 319 Aluminum Alloy. Transactions- American Foundrymen's society 1996, 104, 893-902.

22. Effect of Intermetallic Phase on Microstructure and Mechanical Properties of AA332/Mg2Si(p) Composite. Available online: https://aip.scitation.org/doi/pdf/10.1063/1.4981865 (accessed on 4 December 2019).

23. Campbell, J. Complete Casting Handbook: Metal Casting Processes, Metallurgy, Techniques and Design. Elsevier - Butterworth-Heinemann: Oxford, UK, 2011.

24. Liu, J.; Wang, Q.; Qi, Y. Atomistic simulation of the formation and fracture of oxide bifilms in cast aluminum. Acta Mater. 2019, 164, 673-682. [CrossRef] 
25. Bruna, M.; Remišová, A.; Sládek, G. Effect of Filter Thickness on Reoxidation and Mechanical Properties of Aluminium Alloy AlSi7Mg0.3. Arch. Metall. Mater. 2019, 64, 1100-1106.

26. Capuzzi, S.; Timelli, G.; Fabrizi, A.; Bonollo, F. Influence of Ageing Heat Treatment on Microstructure and Mechanical Properties of a Secondary Rheocast AlSi9Cu3(Fe) Alloy. Mater. Sci. Forum 2015, 828-829, $212-218$. [CrossRef] article distributed under the terms and conditions of the Creative Commons Attribution (CC BY) license (http://creativecommons.org/licenses/by/4.0/). 